\title{
Prevalence and molecular characterization of Staphylococcus aureus from human stool samples
}

\author{
A. E. Kates ${ }^{1}$, D. Thapaliya ${ }^{2}$, T. C. Smith ${ }^{2}$ and M. L. Chorazy $^{3^{*}}$
}

\begin{abstract}
Background: To determine the prevalence of intestinal S. aureus colonization of patients at a large teaching hospital and determine the molecular characteristics of the identified strains. The second objective of this research was to determine risk factors associated with $S$. aureus intestinal colonization.

Methods: A cross-sectional study of 781 specimens from inpatients and outpatients at the University of lowa Hospitals and Clinics Clinical Microbiology Laboratory was conducted. S. aureus was identified using traditional culture methodologies. Methicillin-resistance was determined via PCR of the mecA gene. PVL PCR, spa typing, and antimicrobial sensitivity testing were also done. A nested case-control study was done on a subset of patients with all colonized patients defined as cases and non-colonized controls. Medical record abstractions were done to identify risk factors for intestinal colonization in the nested study.
\end{abstract}

Results: Out of 625 patients included in the final study, 58 were positive for S. aureus (9.3\%). One isolate was positive for the PVL gene. A high number of isolates were resistant to multiple antibiotics including oxacillin (43.1\%), erythromycin (51.7\%), and levofloxacin (41.4\%). All isolates were susceptible to vancomycin, daptomycin, linezolid, and quinupristindalfopristin. In the nested study, having a disease or condition of the gastrointestinal tract significantly increased the odds of intestinal colonization (OR: 1.96, 95\% Cl: 1.04-3.7; aOR: 13.9, 95\% Cl: 1.67-115.7). No other variables were significantly associated with increased odds of colonization.

Conclusions: S. aureus was identified from the stool of patients at the University of lowa Hospitals and Clinics, with a large number of those isolates being resistant to antibiotics and may serve a reservoir for subsequent infections as well as asymptomatic transmission.

Keywords: Methicillin-resistant Staphylococcus aureus, Hospitals, Antibiotic resistance, Intestinal carriage

\section{Background}

Staphylococcus aureus is a commensal bacterium and important cause of healthcare-associated infections [1]. Nasal carriage is considered to be the most important site of S. aureus colonization [2] and is the best-studied [3]. However, other extra-nasal body sites, including the gastrointestinal tract, are known to harbor $S$. aureus [4-6]. Recent studies have found S. aureus in the intestines of healthy humans $[7,8]$ as well as the intestines of hospitalized patients [9].

\footnotetext{
* Correspondence: margaret-chorazy@uiowa.edu

${ }^{3}$ Department of Epidemiology, College of Public Health, University of lowa, lowa City, IA, USA

Full list of author information is available at the end of the article
}

S. aureus, an in particular methicillin-resistant $S$. aureus (MRSA) intestinal colonization, may be more common than previously thought and has been shown to be clinically important $[10,11]$. Rectal carriers have been found to be at increased risk of developing $S$. aureus infections [10] and gastrointestinal carriage of MRSA has been associated with nosocomial antibioticassociated diarrhea [11]. Screening for gastrointestinal carriage has been shown to identify colonized patients who would have been otherwise missed [12]. S. aureus gastrointestinal carriage may be an overlooked reservoir, contributing to hospital infection and transmission.

The objectives of this study were to determine the prevalence of $S$. aureus and MRSA in human stool 
samples at a large university hospital, to characterize the identified isolates by molecular methods, and to assess potential risk factors for intestinal carriage. We hypothesized $S$. aureus and MRSA prevalence in stool will be similar to what has been reported previously in the literature [3]. Furthermore, we hypothesized having a gastrointestinal condition would increase the risk of intestinal S. aureus carriage.

\section{Methods}

\section{Population and design}

We conducted a cross-sectional study of 781 stool specimens retrieved from the University of Iowa Hospitals and Clinics (UIHC) Clinical Microbiology Laboratory between September 2010 and March 2011. UIHC is Iowa's only comprehensive academic medical center, consisting of 811 beds. Though patients are primarily drawn from eastern Iowa, the hospital serves the entire state and into the region beyond (including parts of Illinois, Wisconsin, Minnesota). The specimens were provided from a bank of existing biologic specimens originally collected for the purpose of patient clinical care as part of standard clinical practice. Samples remaining after completion of diagnostics that would have otherwise been disposed by the Clinical Microbiology Laboratory were collected by the researchers and stored at $-80{ }^{\circ} \mathrm{C}$ for further analysis. This convenience sample included both inpatients and outpatients from Iowa, Northern Missouri, and Western Illinois. A nested case-control study was conducted using electronic patient medical records to assess potential risk factors for $S$. aureus intestinal carriage. All patients positive for intestinal $S$. aureus carriage were included in the nested study and considered cases. Two controls were chosen for every case based on admission date and time of stool sample collection within $\pm 24 \mathrm{~h}$. Only one stool sample per patient was included. If more than one stool sample per patient was included in the biobank, only the first stool provided by the patient was included in this analysis.

\section{Ethics, consent, and approval}

The University of Iowa Institutional Review Board approved all study protocols.

\section{Identification and characterization of S. aureus}

$50 \mu \mathrm{L}$ of stool was plated onto Baird-Parker Agar and CHROMagar MRSA media (Becton Dickinson and Company, Sparks, Maryland, USA) and incubated for $48 \mathrm{~h}$ at $35^{\circ} \mathrm{C}$. Presumptive positive colonies were streaked onto Columbia CNA with 5\% sheep blood (Becton Dickinson and Company, Sparks, Maryland, USA), and incubated for $24 \mathrm{~h}$ at $35^{\circ} \mathrm{C}$. All isolates were tested for $S$. aureus using the catalase, coagulase, and
Pastorex Staph Plus rapid latex agglutination (Bio-Rad, Redmond, Washington, USA) tests. Any patient who was culture positive for $S$. aureus and/or MRSA in the stool was considered intestinally colonized.

All S. aureus isolates were tested for antimicrobial susceptibility using broth dilution as described by the Clinical and Laboratory Standards Institute [13]. Isolates were tested for susceptibility to oxacillin, tetracycline, erythromycin, clindamycin, trimethoprimsulfamethoxazole, gentamycin, levofloxacin, vancomycin, daptomycin, quinupristin/dalfopristin, linezolid, and rifampin.

Whole, genomic DNA was extracted using the Wizard Genomic DNA purification kit (Promega Corporation, Madison, Wisconsin, USA) adapted for $S$. aureus. Presence of the $m e c A$ [14] and PVL [15] genes were determined through end-point PCR. spa typing was carried out using the primers and methodologies described by Ridom Bioinformatics and sequences were interpreted utilizing the Ridom StaphType software (Ridom GmbH, Würzburg, Germany). For phenotypically MRSA isolates negative for the mecA gene, the presence of the $m e c C$ gene was determined [16]. All molecular procedures were carried out using known positive and negative controls, including USA300 (mecA, PVL) and LGA251 (mecC).

\section{Medical record abstraction}

Medical record abstractions were done on all $S$. aureus and MRSA-positive patients (cases) and two culturenegative patients (controls). Controls were chosen based on date of admission and time of sample collection relative to cases. Demographic information (gender, age, and race/ethnicity), reason for specimen collection, hospital admission and discharge dates, ICU admission and discharge dates, death date, co-infections, recent antimicrobial use, recent anti-motility medication use, history of gastrointestinal disorders, and history of immunosuppressive conditions were abstracted from the electronic medical record.

\section{Statistical analysis}

Statistical analyses were performed using SAS, version 9.3 (SAS Institute, Cary, NC). There were 781 banked samples available to the investigators from the UIHC. Two controls for each case was decide upon because it has been shown more than two controls per case does not greatly increase the statistical power of the analysis [17]. Logistic regression was performed to assess risk factors for intestinal colonization. The primary exposure of interest, having a disorder of the gastrointestinal tract, was modeled as dichotomous (yes/no). Backwards selection was used to determine which variables to include into the model ( $p>0.2$ threshold to stay in the model). 
Interaction terms were assessed between all covariates. If the term was significantly associated with $S$. aureus infections, it was included into the final model and the Akaike information criterion (AIC) was assessed. If the model including the interaction term increased the AIC by more than three over the model without the term, the interaction term was not included in the final model. Odds ratios and 95\% Confidence Intervals were calculated and a significance level of $p=.05$ was used.

\section{Results}

Of the 781 samples retrieved from the UIHC Clinical Microbiology Laboratory, six samples were excluded due to the tubes breaking during the freezing process. An additional 148 samples were excluded due to patients providing more than one stool sample and six additional samples were excluded due to medical records that were not able to be located, leaving 621 patients included in the study (Fig. 1). Demographic and clinical characteristics of the 621 patients included in the study are described in Table 1. The average age for all patients was 51.6 years (stan. Dev.: 19 years, range: 0 to 94 years). A majority of patients were female $(320,51.5 \%)$ and Caucasian (560, 90.2\%). A majority were inpatients (487, $78.4 \%)$ with $20.1 \%(126 / 625)$ being outpatients, and $1.3 \%$ (8/625) being housed outpatients. The average length of stay for inpatients as defined as the entire time they were admitted for the stay when their stool samples was collected was 15.8 days (stan. Dev.: 28.6 days). There were no significant differences between carriers and non-carriers for any variables listed in Table 1.

Of the 621 samples, $58(58 / 621,9.3 \%)$ were positive for $S$. aureus, 26 of which $(26 / 621,4.2 \%)$ were MRSA via the presence of the $m e c A$ gene, with an MRSA prevalence of $44.8 \%$ (26/58). One isolate was positive for PVL.
Thirty unique spa types were identified, with t002 being the most prevalent at $66.7 \%(n=20)$ followed by $t 012$ and 1635 both at $10 \%(n=3)$. The BURP analysis resulted in one major cluster with the hospitalassociated strain t002 as the founder. The spa cc-002 grouping accounted for 24 strains (42\% of all strains) and four spa types (13\% of all spa types). Two spa types (three isolates) were excluded as they had less than 5 repeat sequences present in the spa gene.

Antimicrobial susceptibility testing was performed on all isolates positive for S. aureus (Fig. 2). Resistance was observed for most antibiotics tested. The highest prevalence of resistance was to erythromycin at $51.7 \%(n=37)$ followed by oxacillin at $43.1 \%(n=25)$ and levofloxacin at $41.4 \%(n=24)$. Resistance to clindamycin was observed at $22.4 \%(n=16)$. No isolates were resistant to vancomycin, daptomycin, or quinupristin/dalfopristin. Resistance to all other antimicrobials was low (Fig. 3). Twenty-six (44.8\%) isolates met the definition for multi-drug resistance (MDR) with having acquired non-susceptibility to at least one agent in three or more antimicrobial categories [18]. Of the MDR isolates, one isolate was resistant to at least one agent in six antimicrobial categories and one isolate was resistant to $\geq 1$ agent in five categories. Twelve isolates were resistant to $\geq 1$ agent in four categories and 9 isolates were resistant to $\geq 1$ agent in 3 categories. Three isolates met the definition of MDR by being MRSA. Twenty-two of the 58 isolates (37.9\%) were susceptible to all antibiotics tested. Six isolates (10.3\%) were resistant to only one antimicrobial and two were resistant to two antimicrobials (3.4\%). Two isolates were phenotypically resistant to oxacillin according to the AST (both isolates had a minimum inhibitory concentration

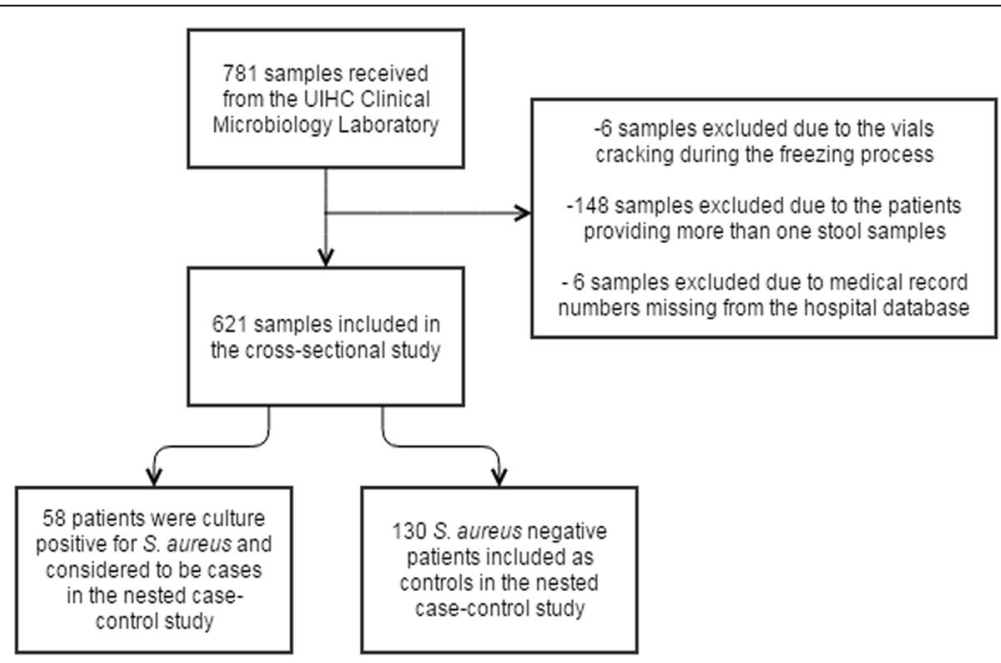

Fig. 1 Flow chart of the participant inclusion and exclusion criteria 
Table 1 Patient demographic data by S. aureus intestinal colonization status

\begin{tabular}{|c|c|c|c|c|}
\hline & $\begin{array}{l}\text { Carriers } \\
n=58\end{array}$ & $\begin{array}{l}\text { Non-carriers } \\
n=567\end{array}$ & $P$ & $\begin{array}{l}\text { Total } \\
n=621\end{array}$ \\
\hline $\begin{array}{l}\text { Age (Mean years } \pm \\
\text { Std. dev.) }\end{array}$ & $51.2( \pm 20.4)$ & $51.6( \pm 18.9)$ & 0.897 & $51.6( \pm 19.0)$ \\
\hline \multicolumn{5}{|l|}{ Sex } \\
\hline Male & $24(41.4 \%)$ & $277(49.2 \%)$ & & $301(48.5 \%)$ \\
\hline Female & $34(58.6 \%)$ & $286(50.8 \%)$ & 0.256 & $320(51.5 \%)$ \\
\hline \multicolumn{5}{|l|}{ Race/ Ethnicity } \\
\hline Caucasian & $52(89.7 \%)$ & $508(90.2 \%)$ & & $560(90.2 \%)$ \\
\hline African American & $2(3.5 \%)$ & $24(4.3 \%)$ & & $26(4.2 \%)$ \\
\hline Hispanic or Latino & $3(5.2 \%)$ & $8(1.4 \%)$ & & $11(1.8 \%)$ \\
\hline Other ${ }^{a}$ & $1(1.7 \%)$ & $24(4.2 \%)$ & 0.486 & $25(4.0 \%)$ \\
\hline \multicolumn{5}{|l|}{ Visit Type } \\
\hline Inpatient & $44(75.9 \%)$ & $443(78.7 \%)$ & & 487 (78.4\%) \\
\hline Outpatient & $13(22.4 \%)$ & $113(20.1 \%)$ & & $126(20.3 \%)$ \\
\hline Housed outpatient ${ }^{\mathrm{b}}$ & $1(1.7 \%)$ & $7(1.2 \%)$ & 0.865 & $8(1.3 \%)$ \\
\hline $\begin{array}{l}\text { Length of Stay (Mean } \\
\text { days } \pm \text { Std. dev.) }\end{array}$ & $21.7( \pm 51.7)$ & $15.2( \pm 25.1)$ & 0.992 & $15.8( \pm 28.6)$ \\
\hline
\end{tabular}

${ }^{\mathrm{b}}$ Housed outpatient refers to patients being held for observation
[MIC] of $\geq 4 \mu \mathrm{g} / \mathrm{mL}$ ); however, both isolates were negative for the presence of the mecA and mecC genes.

Medical record abstractions were completed on 189 patients (58 cases and 131 controls). A majority of cases were Caucasian $(n=168,88.9 \%)$ and slightly over half were male $(n=98,51.8 \%)$. In the univariate analysis, most covariates were not significantly associated with $S$. aureus intestinal colonization. We observed a borderline significant association with sex with females having increased odds of intestinal colonization, though the confidence interval included 1.0 (OR: 1.84, 95\% CI: 0.98-3.44). Having a history of a gastrointestinal condition, the primary predictor, was significant in the unadjusted, univariate model with those having any disorder of the gastrointestinal tract having increased odds of intestinal colonization (OR: 1.96, 95\% CI: 1.04-3.7). The most prevalent disorder of the GI tract was gastroesophageal reflux disease (GERD) at 31 of the 189 patients $(16.4 \%)$ of the total population analyzed for the nested study. The second most prevalent condition was lower GI bleed ( $n=16,7.4 \%)$ followed by Crohn's disease $(n=13,6.9 \%)$ and any inflammatory disorder of the intestines including inflammatory bowel disorder $(n=13,6.9 \%)$. No other covariates were significantly associated with intestinal colonization in the univariate analyses (Table 2).

The final adjusted model included having a disorder of the gastrointestinal tract, age, sex, laxative usage, antimotility agent usage, having a $S$. aureus infection, whether the patient died, ICU length of stay, and the reason for specimen collection. An interaction between having a gastrointestinal disorder and age was forced

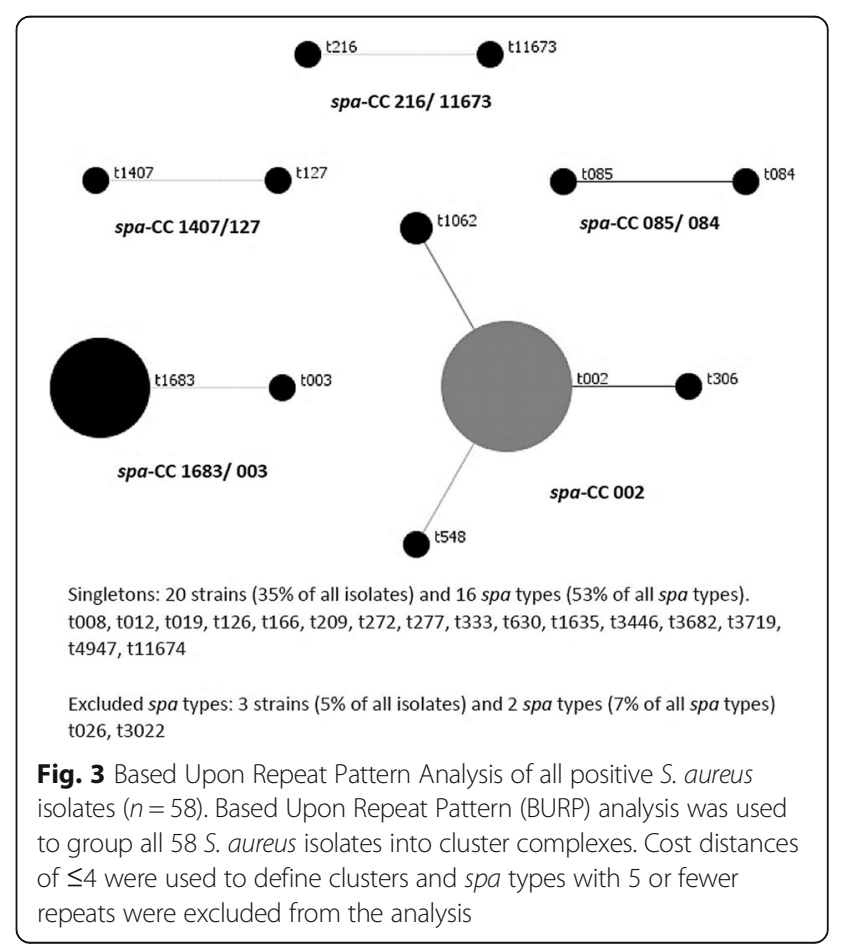


Table 2 Associations between potential risk factors and S. aureus intestinal colonization

\begin{tabular}{|c|c|c|c|c|}
\hline Risk Factor & $\begin{array}{l}\text { Cases } \\
(\mathrm{N}=58)\end{array}$ & $\begin{array}{l}\text { Controls } \\
(N=131)\end{array}$ & $\begin{array}{l}\text { Unadjusted } \\
\text { OR (95\% Cl) }\end{array}$ & $\begin{array}{l}\text { Adjusted } \\
\text { OR }(95 \% \text { Cl) }\end{array}$ \\
\hline \multicolumn{5}{|l|}{ Age } \\
\hline $0-29$ years & 9 & 13 & Ref & Ref \\
\hline $30-49$ years & 14 & 34 & $0.58(0.020-1.65)$ & $2.94(0.43-19.88)$ \\
\hline $50-69$ years & 28 & 60 & $0.67(0.026-1.77)$ & $5.02(0.81-30.9)$ \\
\hline Over 70 years & 7 & 23 & $0.44(0.13-1.5)$ & $1.42(0.15-13.6)$ \\
\hline \multicolumn{5}{|l|}{ Sex } \\
\hline Male & 24 & 74 & Ref & Ref \\
\hline Female & 33 & 58 & $1.84(0.98-3.44)$ & $1.93(0.94-3.96)$ \\
\hline \multicolumn{5}{|l|}{ Race/ Ethnicity } \\
\hline Caucasian & 53 & 115 & Ref & \\
\hline African American & 2 & 5 & $0.9(0.17-4.8)$ & \\
\hline Hispanic/ Latino & 3 & 2 & $3.35(0.54-20.63)$ & \\
\hline Other & 1 & 8 & $0.28(0.03-2.29)$ & \\
\hline \multicolumn{5}{|l|}{ S. aureus Infection ${ }^{a}$} \\
\hline No & 53 & 121 & Ref & Ref \\
\hline Yes & 5 & 10 & $1.14(0.37-3.50)$ & $0.83(0.19-3.54)$ \\
\hline \multicolumn{5}{|l|}{ Other Coinfections } \\
\hline No Coinfections & 26 & 46 & Ref & \\
\hline One & 21 & 60 & $0.62(0.34-1.23)$ & \\
\hline Two & 4 & 18 & $0.49(0.16-1.48)$ & \\
\hline Three or more & 7 & 7 & $0.67(0.19-2.34)$ & \\
\hline \multicolumn{5}{|l|}{ Collection Reason } \\
\hline Abdominal pain & 5 & 13 & Ref & Ref \\
\hline Clostridium difficile & 23 & 37 & $1.61(0.51-5.13)$ & $1.87(0.49-7.11)$ \\
\hline Diarrhea & 11 & 72 & $0.67(0.21-2.14)$ & $0.59(0.15-2.25)$ \\
\hline Other & 19 & 9 & $2.25(0.63-8.03)$ & $2.74(0.64-11.7)$ \\
\hline \multicolumn{5}{|l|}{ Deceased $^{b}$} \\
\hline No & 44 & 83 & Ref & Ref \\
\hline Yes-within 30 days & 3 & 11 & $0.71(0.18-2.8)$ & $0.74(0.13-4.67)$ \\
\hline Yes- after 30 days & 14 & 26 & $0.4(0.16-0.98)$ & $0.29(0.1-0.86)$ \\
\hline Undeterminable & 4 & 7 & $1.08(0.3-3.9)$ & $0.71(0.17-2.96)$ \\
\hline \multicolumn{5}{|l|}{ Gastrointestinal Disease } \\
\hline No & 21 & 69 & Ref & Ref \\
\hline Yes & 37 & 62 & $1.96(1.04-3.7)$ & $13.9(1.67-115.7)$ \\
\hline \multicolumn{5}{|l|}{ Immunocompromised } \\
\hline No & 15 & 34 & Ref & \\
\hline Yes & 43 & 97 & $1.01(0.47-2.04)$ & \\
\hline \multicolumn{5}{|l|}{ ICU Stay } \\
\hline No & 47 & 98 & Ref & \\
\hline Yes & 11 & 33 & $0.69(0.32-1.5)$ & \\
\hline \multicolumn{5}{|l|}{ ICU Unit } \\
\hline No ICU stay & 47 & 98 & Ref & \\
\hline MICU & 5 & 21 & $0.5(0.18-1.4)$ & \\
\hline
\end{tabular}


Table 2 Associations between potential risk factors and S. aureus intestinal colonization (Continued)

\begin{tabular}{|c|c|c|c|c|}
\hline Risk Factor & $\begin{array}{l}\text { Cases } \\
(\mathrm{N}=58)\end{array}$ & $\begin{array}{l}\text { Controls } \\
(N=131)\end{array}$ & $\begin{array}{l}\text { Unadjusted } \\
\text { OR (95\% CI) }\end{array}$ & $\begin{array}{l}\text { Adjusted } \\
\text { OR (95\% Cl) }\end{array}$ \\
\hline SICU & 2 & 6 & $0.7(0.14-3.58)$ & \\
\hline Other & 4 & 6 & $1.4(0.4-5.2)$ & \\
\hline \multicolumn{5}{|l|}{ ICU Length of Stay } \\
\hline 0 days & 47 & 99 & Ref & Ref \\
\hline 1 to 4 days & 1 & 14 & $0.15(0.02-1.18)$ & $0.15(0.02-1.36)$ \\
\hline Greater than 4 days & 10 & 18 & $1.18(0.5-2.73)$ & $1.38(0.46-4.15)$ \\
\hline \multicolumn{5}{|l|}{ Total Length of Stay } \\
\hline 0 days & 12 & 23 & Ref & \\
\hline 1 to 10 days & 23 & 59 & $0.75(0.32-1.75)$ & \\
\hline 11 to 29 days & 10 & 26 & $0.74(0.27-2.02)$ & \\
\hline Greater than 30 days & 13 & 23 & $1.08(0.41-2.87)$ & \\
\hline \multicolumn{5}{|l|}{ Antibiotics used } \\
\hline No & 26 & 40 & Ref & \\
\hline Yes & 32 & 91 & $0.54(0.29-1.02)$ & \\
\hline \multicolumn{5}{|l|}{ Laxatives used } \\
\hline No & 43 & 100 & Ref & Ref \\
\hline Yes & 15 & 31 & $1.13(0.56-2.3)$ & $1.94(0.8-4.6)$ \\
\hline \multicolumn{5}{|l|}{ Anti-motility agent used } \\
\hline No & 57 & 122 & Ref & Ref \\
\hline Yes & 1 & 9 & $0.238(0.03-1.92)$ & $0.16(0.02-1.53)$ \\
\hline
\end{tabular}

${ }^{\mathrm{a} S}$. aureus infections are defined as clinical infections extracted from the patients medical record

${ }^{\mathrm{b}}$ Mortality is not considered a risk factor colonization. For this variable, S. aureus colonization is a risk factor for mortality

into the model as the interaction term was verging on significance $(p=0.058)$ and did not increase the AIC by more than 3. In the final model, having a disorder of the GI tract was significantly associated with increased odds of being intestinally colonized with $S$. aureus, though the confidence interval is very wide (OR: $13.9,95 \%$ CI: $1.67-$ 115.7). No other covariates included in the final model were significantly associated with intestinal $S$. aureus colonization (Table 2).

\section{Discussion}

We identified $S$. aureus in the intestines of patients at UIHC and report an intestinal colonization rate of 9.3\%. During the 1950's, S. aureus intestinal colonization was studied in greater detail than seen in the current literature [19]. Studies from this time report carriage prevalence ranges between $8 \%$ and $30 \%[3,20,21]$. While researchers have known of the relationship between intestinal $S$. aureus carriage and antibiotic-associated diarrhea, as well as the increased risk of other $S$. aureus infections, intestinal carriage has been studied far less than carriage at other anatomical sites, particularly the nares. Recent studies of $S$. aureus intestinal carriage have detected intestinal carriage rates ranging from 10\% [22] to as high as $37 \%$ [10]. It has been estimated the average rate of intestinal colonization in hospitalized patients is roughly $20 \%$ [3], though the number of studies included in reaching this estimate is small and the populations vary greatly. Our observed prevalence of $9.3 \%$ is lower than the estimated average and lower than most studies have reported to date. This may be due to the fact the population screened for this study included patients from many departments across a large teaching hospital as well as outpatients seen in the emergency department. Use of frozen instead of fresh stools may also have reduced our recovery rate.

Many of the studies in recent years have focused on MRSA carriage and have reported MRSA intestinal carriage rates frequently ranging from $5 \%[22,23]$ to $10 \%$ [24] with some studies finding a MRSA prevalence as high as $22 \%$ in high-risk populations [25]. The observed prevalence of MRSA reported here is $4.2 \%$, which is lower than others have reported. Of the $S$. aureus isolates identified, $44.8 \%$ met the definition for MDR-SA. Two of these isolates were phenotypically resistant to oxacillin; however, they were not positive for either resistance gene - mecA or mecC -tested for.

We found one isolate to be positive for the PVL gene [26]. As PVL genes are mainly associated with community-associated $S$. aureus, it is not surprising we found 
such a low prevalence in clinical cohort. Spa type t002 was the most frequently identified spa type accounting for $66.7 \%$ of all identified spa types. This spa type is most frequently associated with hospital strains and typically belongs to the pulsed-field type USA100 [27]. Spa type t012, the second most prevalent spa type observed in this study ( $10 \%$ of all spa types) is frequently found in community settings and may be associated with younger age [28].

Prevalence of intestinal carriage is dependent on the method of specimen collection employed. Varying rates of colonization are seen by method and anatomical site used to define "gastrointestinal." The two main methods used to collect specimens are swabs and stool samples. Swabs collected from the rectum, anus, perineum, and the groin or inguinal region are typically accepted as representing intestinal carriage of $S$. aureus in addition to stool specimens [3]. Several studies have assessed which method and region provide the most consistent rate of colonization, but these studies are few and do not provide a consensus. Rectal swabbing has been shown to yield more $S$. aureus than stool cultures [29]. This may explain why our study reports a lower prevalence compared to many of the studies cited above which used rectal or perineal swabbing.

Intestinal colonization may be an important reservoir for the dissemination of $S$. aureus in the health care setting. Intestinal colonization is known to lead to increased risk of infection [30-32], though the mechanism is not clear. It has been hypothesized intestinal colonization increases colonization or contamination of the skin which in turn increases contamination of the patient's environment. Environmental contamination then increases both the risk of infection as well as the potential for nosocomial transmission [31]. While we were unable to investigate colonization of other body sites in this study, S. aureus intestinal colonization has been associated with an increased risk of skin colonization [10]. Nasal and intestinal carriage are also frequently observed in the same patient; however, intestinal colonization alone does increase the detection sensitivity [3, 22, 23, 33-35]. In a meta-analysis by McKinnell et al., it was found rectal screening increased yield by $20 \%$, with rectal screening having the greatest impact in hospitals with a low MRSA prevalence (23\% increase) [35].

To assess potential risk factors for intestinal colonization, we performed a nested case-control study. We hypothesized having a disease or condition of the gastrointestinal tract would put patients at increased risk of $S$. aureus intestinal colonization. In the univariate analysis we found gastrointestinal conditions did significantly increase the odds of being colonized with S. aureus (OR: 1.96, 95\% CI: 1.04-3.7) and this association remained significant after adjusting for the other variables included in the final model (OR: 13.9, 95\% CI: 1.67-115.7), though the 95\% confidence interval was very wide due to a small sample size. No other variables abstracted from the medical record were significantly associated with an increased risk of intestinal colonization in either the univariate or adjusted models. Other studies have reported several potential risk factors for intestinal $S$. aureus colonization. It has been shown that a stay in an extended care facility or nursing home can significantly increase the risk of intestinal colonization [36]; however, we were unable to assess nursing home stays in the present study. Studies have also reported length of stay [37], a recent history of antimicrobial usage [37-39], a history of MRSA infection [38], and dependence on healthcare workers to perform activities of daily living [37] all significantly increasing the risk of intestinal S. aureus carriage. While we were not able to assess activities of daily living in the medical record, we did not detect a significant association with LOS, antibiotic usage, or the history of MRSA infections and colonization in our population. This may be due to the inclusion of a single hospital in this study, smaller sample size, and the reliance on medical record data.

Our study has several limitations. The first is the specimens analyzed were not collected for research purposes, but for routine medical care and as such we were only able to address intestinal colonization in a cross-sectional study and were unable to determine the duration of colonization in these patients. Future studies are needed to determine colonization duration, as well as the rates of persistent versus intermittent carriage. Furthermore, we were unable to determine if the $S$. aureus strain the patient was colonized with was the same strain causing an $S$. aureus infection, or otherwise present in other locations of the patient's body or environment. This study was conducted in a single hospital in Iowa with a predominantly white population which may limit the generalizability of the study findings. However, UIHC is a large teaching hospital with a catchment area including several surrounding mid-western states. $S$ aureus was identified from the stool of patients at the UIHC. Lastly, the samples used for this study were collected as part of routine clinical care and as such, all participants had some degree of gastrointestinal symptoms. A history of gastrointestinal conditions increased the risk of intestinal S. aureus carriage. Many of those isolates are resistant to antibiotics and may serve as a reservoir for subsequent infections and transmission events.

\section{Conclusions}

S. aureus colonization was found in $9.3 \%$ of tested stool samples. Having a disease or condition of the gastrointestinal tract significantly increased the odds of intestinal colonization. A diverse array of molecular types were isolated, and antibiotic resistance was common, including methicillin resistance and multi-drug resistant strains. 


\section{Abbreviations}

AIC: Akaike information criterion; BURP: Based Upon Repeat Pattern.; GERD: Gastroesophageal reflux disease; LOS: Length of stay; MDR: Multi-drug resistant; MIC: Minimum inhibitory concentration; MRSA: Methicillin-resistant Staphylococcus aureus; UIHC: University of lowa Hospitals and Clinics

\section{Acknowledgements}

The authors would like to thank the Clinical Microbiology Laboratory and the University of lowa Hospitals and Clinics and Dr. Bradley Ford for their assistance with medical record abstraction. Thanks to Yesenia C. Romero-Herazo for retrieving the specimens.

\section{Funding}

No funding was received.

\section{Availability of data and materials}

Data are available upon request to authors.

\section{Authors' contributions}

Conception and design of the study: AK, MC, TS. Acquisition of data: AK, MC. Molecular characterization: AK, DT. Analysis and interpretation of data: AK DT. Drafting and revising of the manuscript: all authors. Final approval of the manuscript: all authors.

Ethics approval and consent to participate

This study was approved by the University of lowa IRB.

\section{Consent for publication}

Not applicable.

\section{Competing interests}

The authors declare that they have no competing interests.

\section{Publisher's Note}

Springer Nature remains neutral with regard to jurisdictional claims in published maps and institutional affiliations.

\section{Author details}

'Division of Infectious Disease, Department of Medicine, School of Medicine and Public Health, University of Wisconsin-Madison, Madison, WI, USA. ${ }^{2}$ Department of Biostatistics, Epidemiology and Environmental Health Services, College of Public Health, Kent State University, Kent, OH, USA. ${ }^{3}$ Department of Epidemiology, College of Public Health, University of lowa, lowa City, IA, USA.

Received: 21 November 2017 Accepted: 1 March 2018

Published online: 20 March 2018

References

1. Wertheim HF, Melles DC, Vos MC, van Leeuwen W, van Belkum A, Verbrugh HA, Nouwen $J$. The role of nasal carriage in Staphylococcus aureus infections. Lancet Infect Dis. 2005:5(12):751-62.

2. Williams RE. Healthy carriage of Staphylococcus aureus: its prevalence and importance. Bacteriol Rev. 1963:27:56-71.

3. Acton DS, Plat-Sinnige MJ, van Wamel W, de Groot N, van Belkum A. Intestinal carriage of Staphylococcus aureus: how does its frequency compare with that of nasal carriage and what is its clinical impact? Eur Clin Microbiol Infect Dis. 2009;28(2):115-27.

4. Wertheim HF, Verveer J, Boelens HA, van Belkum A, Verbrugh HA, Vos MC. Effect of mupirocin treatment on nasal, pharyngeal, and perineal carriage of Staphylococcus aureus in healthy adults. Antimicrob Agents Chemother. 2005;49(4):1465-7.

5. Ridley M. Perineal carriage of Staph. Aureus. Br Med J. 1959;1(5117):270-3.

6. Rimland D, Roberson B. Gastrointestinal carriage of methicillin-resistant Staphylococcus aureus. J Clin Microbiol. 1986:24(1):137-8.

7. Benito D, Lozano C, Gomez-Sanz E, Zarazaga M, Torres C. Detection of methicillin-susceptible Staphylococcus aureus ST398 and ST133 strains in gut microbiota of healthy humans in Spain. Microb Ecol. 2013;66(1):105-11.

8. Gurnee EA, Ndao IM, McGhee JE, Warner BB, Tarr PI, Fritz SA, Burnham CA. Fecal carriage of methicillin-resistant Staphylococcus aureus and vancomycin-resistant enterococcus in healthy children. Antimicrob Agents Chemother. 2014;58(2):1261-2

9. Nakao A, Ito T, Han X, Lu YJ, Hisata K, Tsujiwaki A, Matsunaga N, Komatsu M Hiramatsu K, Shimizu T. Intestinal carriage of methicillin-resistant Staphylococcus aureus in nasal MRSA carriers hospitalized in the neonatal intensive care unit. Antimicrob Resist Infect Control. 2014;3:14.

10. Bhalla A, Aron DC, Donskey CJ. Staphylococcus aureus intestinal colonization is associated with increased frequency of S. Aureus on skin of hospitalized patients. BMC Infect Dis. 2007;7:105.

11. Boyce JM, Havill NL. Nosocomial antibiotic-associated diarrhea associated with enterotoxin-producing strains of methicillin-resistant Staphylococcus aureus. Am J Gastroenterol. 2005;100(8):1828-34

12. Nishikawa M, Tanaka T, Nakashima K, Senda K, Shibasaki M, Miura H, Tamakoshi A, Ohta T, Yagi T. Screening for methicillin-resistant Staphylococcus aureus (MRSA) carriage on admission to a geriatric hospital. Arch Gerontol Geriatr. 2009;49(2):242-5

13. CLSI. Performance standards for antimicrobial susceptibility testing: twentysecond informational supplement, vol. In: 32: Clinical \& Laboratory Standards Institute; 2012

14. Bosgelmez-Tinaz G, Ulusoy S, Aridogan B, Coskun-Ari F. Evaluation of different methods to detect oxacillin resistance in Staphylococcus aureus and their clinical laboratory utility. Eur J Clin Microbiol Infect Dis. 2006;25(6):410-2.

15. Lina G, Piemont Y, Godail-Gamot F, Bes M, Peter MO, Gauduchon V, Vandenesch F, Etienne J. Involvement of Panton-valentine leukocidinproducing Staphylococcus aureus in primary skin infections and pneumonia. Clin Infect Dis. 1999:29(5):1128-32.

16. Garcia-Alvarez L, Holden MT, Lindsay H, Webb CR, Brown DF, Curran MD, Walpole E, Brooks K, Pickard DJ, Teale C, et al. Meticillin-resistant Staphylococcus aureus with a novel mecA homologue in human and bovine populations in the UK and Denmark: a descriptive study. Lancet Infect Dis. 2011;11(8):595-603.

17. Lewallen S, Courtright P. Epidemiology in practice: case-control studies. Community Eye Health. 1998;11(28):57-8.

18. Magiorakos AP, Srinivasan A Carey RB, Carmeli Y, Falagas ME, Giske CG, Harbarth S, Hindler JF, Kahlmeter G, Olsson-Liljequist B, et al. Multidrugresistant, extensively drug-resistant and pandrug-resistant bacteria: an international expert proposal for interim standard definitions for acquired resistance. Clin. Microbiol. Infect. 2012;18(3):268-81.

19. Altemeier WA, Hummel RP, Hummel RP, Hill EO. Staphylococcal enterocolitis following antibiotic therapy. Ann Surg. 1963:157:847-58.

20. Greendyke RM, Constantine HP, Magruder GB, Dean DC, Gardner JH, Morgan HR. Staphylococci on a medical ward, with special reference to fecal carriers. Am J Clin Pathol. 1958:30(4):318-22.

21. Grun L. Studies on intestinal staphylococci. Arch Hyg Bakteriol. 1958;142(1):3-7.

22. Cavalcanti SM, Franca ER, Cabral C, Vilela MA, Montenegro F, Menezes D, Medeiros AC. Prevalence of Staphylococcus aureus introduced into intensive care units of a university hospital. Braz J Infect Dis. 2005;9(1):56-63.

23. Eveillard M, de Lassence A, Lancien E, Barnaud G, Ricard JD, Joly-Guillou ML. Evaluation of a strategy of screening multiple anatomical sites for methicillinresistant Staphylococcus aureus at admission to a teaching hospital. Infect Control Hosp Epidemiol off j Soc Hosp Epidemiol Am. 2006;27(2):181-4.

24. Roghmann MC, Gorman PH, Wallin MT, Kreisel K, Shurland S, Johnson JA. Staphylococcus aureus colonization in community-dwelling people with spinal cord dysfunction. Arch Phys Med Rehabil. 2007;88(8):979-83.

25. Grmek-Kosnik I, Ihan A, Dermota U, Rems M, Kosnik M, Jorn Kolmos H. Evaluation of separate vs pooled swab cultures, different media, broth enrichment and anatomical sites of screening for the detection of methicillin-resistant Staphylococcus aureus from clinical specimens. J hosp infect. 2005:61(2):155-61.

26. Vandenesch F, Naimi T, Enright MC, Lina G, Nimmo GR, Heffernan H, Liassine N, Bes M, Greenland T, Reverdy ME, et al. Community-acquired methicillin-resistant Staphylococcus aureus carrying Panton-valentine leukocidin genes: worldwide emergence. Emerg Infect Dis. 2003;9(8):978-84

27. McDougal LK, Steward CD, Killgore GE, Chaitram JM, MCAllister SK, Tenover FC. Pulsed-field gel electrophoresis typing of oxacillin-resistant Staphylococcus aureus isolates from the United States: establishing a national database. J Clin Microbiol. 2003;41(11):5113-20.

28. Sangvik M, Olsen RS, Olsen K, Simonsen GS, Furberg AS, Sollid JU. Age- and gender-associated Staphylococcus aureus spa types found among nasa carriers in a general population: the Tromso staph and skin study. J Clin Microbiol. 2011;49(12):4213-8. 
29. Crossley K, Solliday J. Comparison of rectal swabs and stool cultures for the detection of gastrointestinal carriage of Staphylococcus aureus. J Clin Microbiol. 1980;11(4):433-4.

30. Tulloch LG, Alder VG, Gillespie WA. Treatment of chronic furunculosis. Br Med J. 1960;2(5195):354-6.

31. Squier C, Rihs JD, Risa KJ, Sagnimeni A, Wagener MM, Stout J, Muder RR, Singh N. Staphylococcus aureus rectal carriage and its association with infections in patients in a surgical intensive care unit and a liver transplant unit. Infect control hosp epidemiol off j Soc Hosp Epidemiol Am. 2002;23(9):495-501.

32. Solberg CO. A study of carriers of Staphylococcus aureus with special regard to quantitative bacterial estimations. Acta Medica Scand Suppl. 1965:436:1-96.

33. Mody L, Kauffman CA, Donabedian S, Zervos MJ, Bradley SF. Epidemiology of Staphylococcus aureus colonization in nursing home residents. Clin infect dis off publ Infect Dis Soc Am. 2008;46(9):1368-73.

34. Simor AE, Ofner-Agostini M, Paton S, McGeer A, Loeb M, Bryce E, Mulvey M. Clinical and epidemiologic features of methicillin-resistant Staphylococcus aureus in elderly hospitalized patients. Infect control hosp epidemiol off j Soc Hosp Epidemiol Am. 2005;26(10):838-41.

35. McKinnell JA, Huang SS, Eells SJ, Cui E, Miller LG. Quantifying the impact of extranasal testing of body sites for methicillin-resistant Staphylococcus aureus colonization at the time of hospital or intensive care unit admission. Infect control hosp epidemiol off j Soc Hosp Epidemiol Am. 2013;34(2):161-70.

36. Lee DC, Barlas D, Ryan JG, Ward MF, Sama AE, Farber BF. Methicillin-resistant Staphylococcus aureus and vancomycin-resistant enterococci: prevalence and predictors of colonization in patients presenting to the emergency department from nursing homes. J Am Geriatr Soc. 2002:50(8):1463-5.

37. Trick WE, Weinstein RA, DeMarais PL, Kuehnert MJ, Tomaska W, Nathan C, Rice TW, McAllister SK, Carson LA, Jarvis WR. Colonization of skilled-care facility residents with antimicrobial-resistant pathogens. J Am Geriatr Soc. 2001;49(3):270-6.

38. Hogardt M, Proba P, Mischler D, Cuny C, Kempf VA, Heudorf U. Current prevalence of multidrug-resistant organisms in long-term care facilities in the Rhine-main district, Germany, 2013. Euro Surveill. 2015;20(26).

39. Papadimitriou-Olivgeris M, Spiliopoulou I, Christofidou M, Logothetis D, Manolopoulou P, Dodou V, Fligou F, Marangos M, Anastassiou ED. Cocolonization by multidrug-resistant bacteria in two Greek intensive care units. Euro j clin microb infect dis off publ Euro Soc Clin Microbiol. 2015; 34(10):1947-55.

\section{Submit your next manuscript to BioMed Central and we will help you at every step:}

- We accept pre-submission inquiries

- Our selector tool helps you to find the most relevant journal

- We provide round the clock customer support

- Convenient online submission

- Thorough peer review

- Inclusion in PubMed and all major indexing services

- Maximum visibility for your research

Submit your manuscript at www.biomedcentral.com/submit

) Biomed Central 